\title{
Uniform Format for Disclosure of Conflict of Interest in the CJHP
}

\author{
Peter J Zed
}

$\mathrm{D}$ isclosure of the actual or perceived conflicts of interest of authors of papers published in the biomedical literature has become standard practice in most journals. The credibility of published articles is dependent, in part, on how well conflicts of interest are handled and reported. A conflict of interest exists when an author has financial or personal relationships that may inappropriately influence or bias his or her actions. Such relationships range from the minor to the significant, and the potential for a conflict of interest may exist regardless of whether the author believes that the relationship affects his or her scientific judgement. Financial relationships, such as employment, stock ownership, consulting, honoraria for speaking, or reimbursement of travel expenses, are the most common and identifiable conflicts of interest and the most likely to undermine the credibility of the authors, the science, and the journal in which the work is published. Disclosure of conflicts allows the reader to evaluate the nature of any relationship between the authors and commercial entities that may have a competing interest in the information presented in the published manuscript.

Despite the fact that many journals require authors to declare their conflicts of interest, there has been no standard to ensure uniform reporting. Authors may provide similar information on conflicts of interest in different formats, which may cause confusion for both the author and the reader. It is also time-consuming for authors to meet the different disclosure requirements of various journals. To address this problem, the International Committee of Medical Journal Editors (ICMJE) has introduced a uniform disclosure form, which has been adopted by all journals that are members of ICMJE, ${ }^{1}$ including the New England Journal of Medicine, The Lancet, the Annals of Internal Medicine, the BMJ, the Journal of the American Medical Association, and the Canadian Medical Association Journal. This uniform reporting process requires authors to disclose 4 types of information where actual or perceived conflict of interest may exist: (1) their associations with commercial entities that provided support for the work reported in the submitted manuscript (during the lifespan of the work under consideration for publication), (2) their associations with commercial entities that could be viewed as having an interest in the general

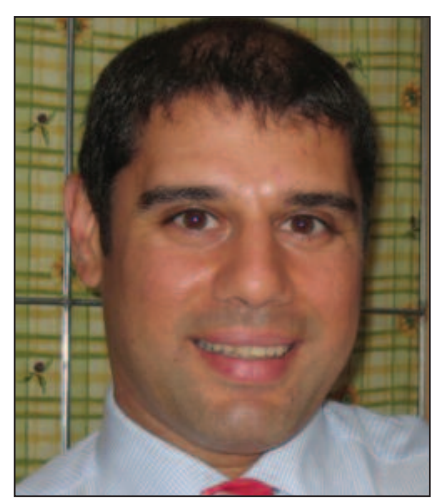
area of the submitted manuscript (in the 36 months before submission), (3) any similar financial associations involving spouses or children under 18 years of age, and (4) nonfinancial associations that may be relevant to the submitted manuscript.

The members of the CJHP Editorial Board believe that this is a significant step forward in the reporting of actual or perceived conflicts of interest, and we have therefore adopted this uniform reporting process and the relevant form for manuscripts submitted to the CJHP. The form, along with instructions for completing it, is now posted on the CJHP website (www.cjhp-online.ca/pages/files/ICMJE_ Disclosure_Form.pdf). Effective immediately, all authors will be required to complete and append this form at the time they submit their manuscript to the CJHP. Although the form appears laborious, it can be downloaded to an individual author's computer to be maintained, updated, and used each time a manuscript is submitted to any journal. The adoption of this uniform disclosure form by the CJHP, as well as by members of the ICMJE and other participating journals, will eliminate the need to reformat conflict of interest forms for specific journals, which will also save authors' time. In addition, each member of the CJHP Editorial Board will complete this form annually. We at the CJHP are grateful to 
our authors, who support the journal through their submissions, and we are also responsive to the needs of our readers. We believe that this uniform format for reporting competing interests is in the best interests of all stakeholders of the CJHP.

\section{Reference}

1. Drazen JM, Van Der Weyden MB, Sahni P, Rosenberg J, Marusic A, Laine C, et al. Uniform format for disclosure of competing interests in ICMJE journals [editorial]. International Committee of Medical Journal Editors; 2009 [cited 2010 Apr 12]. Available from: www.icmje.org/format.pdf
Peter J Zed, BSC, BSc(Pharm), ACPR, PharmD, FCSHP, is Clinical Coordinator, Department of Pharmacy, and Pharmacotherapeutic Specialist-Emergency Medicine, Queen Elizabeth II Health Sciences Centre, and Associate Professor, College of Pharmacy and Department of Emergency Medicine, Dalhousie University, Halifax, Nova Scotia. He is also an Associate Editor with the CJHP.

\section{Address correspondence to:}

Dr Peter J Zed

Department of Pharmacy

Halifax Infirmary

Queen Elizabeth II Health Sciences Centre

1796 Summer Street

Halifax NS B3H 3A7

e-mail: peter.zed@dal.ca

\section{ON THE FRONT COVER}

\section{Gatineau Park, Quebec}

This photograph was taken on October 5, 2008, in Gatineau Park, Quebec. This $361 \mathrm{~km}^{2}$ national park lies northwest of Ottawa, just 15 minutes from Parliament Hill, and is managed by the National Capital Commission. The photographer, Sonya Long, was until recently the CSHP Publications Administrator. The image, taken with a Nikon Digital SLR cam-

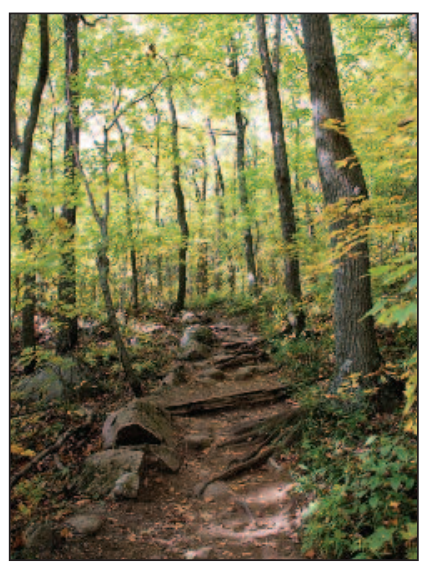

era (model D80), depicts the lush, colourful foliage that Sonya, her husband, and two friends observed while hiking along the trails that afternoon.

The CJHP would be pleased to consider photographs featuring Canadian scenery taken by CSHP members for use on the front cover of the journal. If you would like to submit a photograph, please send an electronic copy (minimum resolution $300 \mathrm{dpi}$ ) to Colleen Drake at cdrake@cshp.ca. 